\title{
World Bank policy lending and the quality of public sector governance
}

\author{
Lodewijk Smetsa,*, Stephen Knack ${ }^{\mathrm{b}}$ \\ ${ }^{a}$ KU Leuven, LICOS Centre for Institutions and Economic Performance, Belgium \\ ${ }^{b}$ World Bank, Washington DC
}

\begin{abstract}
In this study we investigate the impact of World Bank development policy lending for public sector governance on the quality of public sector management and institutions. We measure the latter using the World Bank's Country Policy and Institutional Assessments (CPIA), and consider only policy conditions targeted at improvements in those areas. Using a comprehensive country-year panel dataset of aid receiving countries, we find a significant concave effect of public sector conditions on the quality of public sector governance. These findings are robust to the use of alternative measures of public sector governance and to lagging the variable of interest four periods. Further evidence is provided by employing sample restrictions, adding more controls, and estimating a dynamic model with difference GMM. The optimal number of conditions estimated by our preferred GMM specification is 107 where the predicted policy score is about 0.96 points (1.33 standard deviations) higher than with 0 conditions. We show that conditions related to public financial management are more effective than those related to anti-corruption or civil service and administrative reform, where progress requires changing the behavior of a larger set of deconcentrated actors. We also find evidence that the impact of PSG lending is larger in democracies than in non-democracies. We conclude by describing some innovative ideas in the Bank's ambitious new public sector management strategy that could improve the effectiveness of its support for public sector governance reform.
\end{abstract}

Keywords: policy lending, public sector governance, Aid effectiveness, World Bank 
JEL codes: O10, O19

\section{Introduction}

Since 1980 the World Bank has provided conditional financing to recipient governments to support specific policy and institutional reforms. These budget support operations have become an important component of development finance. During 2009-2012 World Bank policy lending reached about 45 billion USD, and accounts for more than one-fourth of all World Bank lending (World Bank, 2015). In contrast to early adjustment lending, which focused on macroeconomic fundamentals and "getting prices right," the World Bank's development policy loans (DPLs) in recent years seek to improve policy in many different sectors, from agricultural policy to public sector governance (see table 1). There has also been an increased emphasis on government "ownership" of the reform program, with a reduction in the number of conditions or "prior actions" adopted prior to loan disbursement (World Bank, 2015).

Although there is an extensive empirical literature evaluating the effects of adjustment lending on growth and macroeconomic stability, ${ }^{1}$ only a limited number of studies investigate the impact of donor support on a recipient country's public sector. In this study we add to this line of research by examining the association of conditions pertaining to public sector reform in World Bank DPLs with the quality of public sector governance (PSG). The main dependent variable in our study, from the World Bank's Country Policy and Institutional Assessment (CPIA), measures what World Bank country teams are attempting to achieve when they design public sector reform conditions to include in DPLs, i.e., improvements the quality of public sector management. In contrast with the existing

\footnotetext{
${ }^{*}$ Corresponding author

Email addresses: lode.smets@kuleuven.be (Lodewijk Smets), sknack@worldbank.org (Stephen Knack)

${ }^{1}$ See Smets and Knack (2014) for a recent survey of that literature.
} 
literature, we consider the number of cumulative conditions (now called "prior actions") related to public sector governance in DPLs as the main variable of interest. We focus on the accumulation of conditions reflecting the view that support for policy reform in the public sector is a multistage and long-term process (see, e.g., Pritchett and de Weijer, 2010).

Results from panel estimations reveal a significant quadratic relationship, with the quality of public sector governance increasing initially with the number of related prior actions, but decreasing beyond a certain point. These findings are robust to the use of alternative measures of public sector governance and by lagging the variable of interest four periods. Further evidence is provided by employing sample restrictions, adding more controls, and estimating a dynamic model with difference GMM.

The predicted turning point in our preferred GMM specification is at 107 conditions, where the CPIA score on average is about 0.96 points (or 1.33 standard deviations) higher, compared to the case of 0 conditions. There is some suggestive evidence that "backsliding" of reform occurs after loans are fully disbursed. When we drop all annual observations for countries after their last DPL with PSG conditions has closed (i.e., limiting the sample to the period before any backsliding can occur), the maximum impact occurs at 113 conditions, where the CPIA score is 1.24 points higher on average than at 0 conditions.

We also replicate the analyses for governance "sub-sectors" after disaggregating the conditions and CPIA indicators. There are four CPIA indicators on public sector governance: (1) quality of budgetary and financial management, (2) efficiency of revenue mobilization, (3) quality of public administration and (4) transparency, accountability and corruption in the public sector. The PSG-related conditions in DPLs can be classified along similar lines. These disaggregated tests indicate that conditions are effective in supporting public financial management (PFM), but not for promoting accountability, combating corruption and improving quality of public administration. For revenue systems, there is a significant 
quadratic relationship in our preferred GMM specification, but it is not robust to changes in sample or specification. Thus, the positive association between CPIA scores and PSG lending appears to be driven primarily by conditions that support improvements in public financial management.

Finally, as an extended literature points to the importance of political institutions for policy reform (see, e.g., Besley and Persson, 2011), we estimate the main model splitting the sample by regime type. We find significant effects for democracies, which is consistent with the conjecture that inclusive political institutions promote reform and development.

The remainder of this paper is structured as follows. The next section discusses the related empirical literature. In section 3 we review the data and elaborate on the methodology used. Section 4 presents the empirical findings, and section 5 concludes.

\section{Related Literature}

In its early years adjustment lending mainly emphasized economic stabilization and correction of balance of payments distortions (Kapur et al., 1997). At the beginning of the 1990s, however, more emphasis was put on protecting the poor from the adverse effects of adjustment (Dreher, 2002). Furthermore, the development community came to realize that social, political and economic institutions matter for sustained implementation of sound macroeconomic policies, economic growth and poverty reduction (see, e.g., World Bank, 1998). Reflecting these concerns, the Bank's adjustment operations changed along a number of dimensions with an increased attention to public sector governance (PSG). In the 1980s only 24 percent of all conditions in adjustment loans were related to public sector governance. By fiscal year 2007, the share of conditions aimed at improving the public sector had doubled to 50 percent (see figure 1). ${ }^{2}$

\footnotetext{
${ }^{2}$ Other donors are also heavily involved in supporting public sector reform. For instance, Andrews (2013) notes that for the period 2004-2010, more than half of the projects carried out by Britain's Department for International Development (DfID) contained a PSG component.
} 
The available empirical evidence suggests that supporting reforms in the public sector is difficult and success uneven. Cashel-Cordo and Craig (1990) provide an early analysis covering the period 1975-1980. Estimating a fixed-effects model with lagged independent variables, the authors show that the impact of aid on tax collection varies considerably among donors. For instance, Cashel-Cordo and Craig (1990) find that IMF lending reduces government revenues, while loans and grants from bilateral donors do not influence government behavior. Analyzing cross-country data, Knack (2001) finds that higher levels of official development assistance (ODA) diminish the quality of public sector governance - as measured by an index of governance indicators from the International Country Risk Guide (ICRG). ${ }^{3}$ His findings are robust to several sample restrictions, alternative model specifications and correction for endogeneity with 2SLS. Focusing on Sub-Saharan Africa, Brautigam and Knack (2004) repeat this exercise and come to similar conclusions. Furthermore, they find that higher aid levels are associated with a lower effort in tax collection.

Employing OLS on a panel of 84 countries for the period 1984-1995, Alesina and Weder (2002) find tentative evidence that aid increases corruption. They relate their findings to the "voracity effect", i.e. the tendency of foreign aid to foster corruption by increasing the size of resources available (see Svensson, 2000). However, the authors note that they 'cannot fully resolve the question of causality in the relationship between changes in aid and corruption [...] Therefore, these results on the dynamic relationship between aid and corruption have to be taken very cautiously' (Alesina and Weder, 2002, p. 1136). Estimating an error-correction model on a dataset covering the period 1970-1999, Remmer (2004) finds partial evidence that foreign aid reduces the revenue generating effort of lowand middle-income countries. Using fixed effects analysis and IV estimation, Rajan and Subramanian (2007) find that, during the period 1981-1990, foreign aid slowed industry

\footnotetext{
${ }^{3}$ The index from ICRG is an 18-point scale, created by summing the following three six-point scales: corruption in government, bureaucratic quality, and the rule of law.
} 
growth in sectors that are more dependent on government regulation and enforcement of contracts. The authors argue that aid reduces the incentive for governments to invest in rule of law and good governance. In a cross-country regression, de Renzio et al. (2011) investigate the impact of donor support for PFM reform on quality of PFM systems, as measured by Public Expenditure and Financial Accountability (PEFA) assessments. Running OLS on a dataset of 93 countries, the authors find a significantly positive, but economically small effect of donor support for PFM reform on PEFA scores, a result robust to different estimation methods and several sample restrictions. de Renzio et al. (2011) acknowledge that causation could run in both directions, but report that attempts to find 'adequate instrumental variables' were unsuccessful.

A few studies specifically investigate World Bank support for PSG reform, but mostly through project lending rather than DPLs. A large-scale evaluation of PSG lending during 1999-2006 by the World Bank's Independent Evaluation Group (IEG, 2008) - combining a with-without approach, comparison to objectives, before-after analysis with case study findings - suggests that the Bank has been successful in supporting changes in public financial management and tax administration, but has had less success in controlling corruption and improving the functioning of civil service. Cruz and Keefer (2013) show that World Bank public sector reform projects are more likely to be rated as successful in countries with more programmatic political parties. Their explanation is that politicians in those countries have stronger incentives to pursue public policies that require well-functioning public administrations, and therefore to assist rather than block the Bank's reform efforts. Blum (2014) similarly investigates the country and project-level factors associated with higher IEG ratings for PSG projects, finding that they perform better in more democratic and aid-dependent countries. Moloney (2009) estimates the impact of public sector projects on the quality of governance - as measured by Kaufmann et al. (2006) - covering the period 1996-2005. Controlling for GDP per capita and aid over GNI in a random effects model, 
the author reports that World Bank projects have a positive effect on regulatory quality, but a negative impact on control of corruption. Moloney (2009) does not correct for endogeneity, however, and acknowledges that PSG projects may target the most problematic countries. Moreover, due to limited availability of the CPIA data we use in this study, her study relied on other governance indicators "that the Bank itself does not use ...to evaluate its clients." In all of these studies the majority of PSG projects considered are investment loans, not DPLs; Blum (2014) excludes DPLs entirely from his sample.

Our study contributes to this literature in several important ways. First, few previous studies convincingly identify causal effects of aid on public sector performance. We attempt to correct for endogeneity by lagging the variables of interest using difference GMM. Second, our analysis provides a closer match between dependent and independent variables than in most other studies. Rather than testing the effects of aid in general, or DPL conditions in general, on PSG reform, our independent variables measure PSGrelated conditions intended to jump-start improvements in the quality of public sector management and institutions. ${ }^{4}$ In this respect, our study is similar in spirit to Clemens et al. (2012), who show that aid's estimated impact on short-run growth strengthens when humanitarian and other components of aid are excluded that are not intended to further short-run growth. Third, we analyze the impact of conditions on performance for several PSG "sub-sectors" - budgetary management, revenue mobilization, public administration, and transparency, accountability and corruption.

\section{Data and Methodology}

In its first 30 years of policy lending (1980-2010) the World Bank extended 1002 DPLs ${ }^{5}$ to 124 different countries. Table 1 indicates that public sector governance was the primary

\footnotetext{
${ }^{4}$ Note that DPLs each specify intended results that are distinct from and broader than the prior actions contained in the loan (World Bank, 2013).

${ }^{5}$ We have counted DPLs that became effective in 1980 or later.
} 
sector targeted in $13 \%$ of these loans. It is important to note, however, that most of these loans also include conditions pertaining to reforms in other sectors. Similarly, the other 87\% usually include some PSG conditions. Between 2004 and 2012, for example, about $76 \%$ of all DPLs included at least one prior action in PFM (World Bank, 2015). Loans, as classified by the primary sector targeted, may therefore not discriminate very well between support for PSG versus support for reform in other policy areas. For this reason, we use PSG-related conditions as our key independent variable, as they potentially affect the quality of public sector governance, even when they are attached to a loan that mostly targets another sector. ${ }^{6}$

There is considerable variation in PSG lending across countries as shown in figure 2, which presents the distribution of the total number of cumulative PSG-related conditions countries received. Argentina easily tops the list with a total of 210 conditions related to public sector governance, in large part due to the World Bank's involvement in the largescale structural reforms in Argentina during the 1990s and early 2000s (see e.g. Bambaci et al., 2002).

We use the number of cumulative conditions related to public sector governance in DPLs, i.e. the (lagged) sum from all past loans, as the main variable of interest. This choice reflects the view that support for policy reform in the public sector is a multistage and long-term process (see, e.g., Pritchett and de Weijer, 2010). In the area of public sector governance, "prior actions...typically have longer gestation periods" and "often help to build the foundation of an effective state through the passing of laws, elaboration of regulations, and development of institutions - all of which make implementation of sustainable

\footnotetext{
${ }^{6}$ When the tests reported below are replicated, substituting the number of cumulative PSG loans for cumulative PSG conditions, results were not statistically significant. Arguably, this finding is an artifact of measurement error, as many PSG-related conditions are missed by this measure, and many non-PSG conditions are included. For instance, during the 1989-2014 period, 5321 PSG conditions were extended in DPLs that were not coded as PSG loans, and DPLs coded as PSG loans contained 1512 non-PSG conditions.
} 
reforms a gradual process" (World Bank, 2015).

To examine the relationship between cumulative PSG-related conditions and the quality of public sector governance, we estimate the following equation:

$$
y_{i t}=\beta_{0}+\beta_{1} X_{i t}+\beta_{2}\left(X_{i t}\right)^{2}+\beta_{3} Z_{i t}+\delta_{i}+\lambda_{t}+\epsilon_{i t}
$$

where $y_{i t}$ is the CPIA "Cluster D" score for country $i$ in year $t$. CPIA cluster D on public sector management and institutions consists of five components: rule-based governance, quality of budgetary management, efficiency of revenue mobilization, quality of public administration, and transparency, accountability and corruption in the public sector. Countries are rated each year on each of these five dimensions, on a one to six scale. The resulting cluster score is the simple arithmetic mean of the five components. ${ }^{7}$

As CPIA ratings are assessed by World Bank staff, one might argue that results could be driven by spurious correlation or tautological relationships. As a first possibility, CPIA scores for a country could potentially be inflated to justify a shift toward development policy lending (budget support) and away from investment lending (less fungible project aid). Second, over-optimistic beliefs about the efficacy of PSG-related conditionality could be reflected in over-optimistic CPIA assessments, biasing ratings upward. Third, it is possible that PSG-related conditions are selected to match the CPIA criteria, so that their implementation virtually guarantees an improvement in the CPIA ratings. Regarding this last possibility, however, prior actions tend to be modest "de jure" reforms, such as cabinet approval of an access to information law, that would rarely be significant enough to warrant an increase in a CPIA rating. The intent of reforms in this area is to make government more responsive to civil society's demands for information and thereby improve accountability and performance, and the CPIA content reflects these larger objectives rather than the

\footnotetext{
${ }^{7}$ See the appendix for a detailed description of the components and the assessment procedure used to generate them.
} 
mere presence of an access to information law. ${ }^{8}$

Nevertheless, for the above three reasons we have tested our model with two alternative dependent variables, one from the Heritage Foundation and one from the PRS Group. Since 1995 the Heritage Foundation has annually published an index of economic freedom, based on 10 components. We have used the average of two of those components, property rights and freedom from corruption, as an (incomplete) alternative for the CPIA cluster D score. Since the early 1980s, the PRS Group has produced the "International Country Risk Guide" (ICRG) ratings, including assessments of corruption in government, the strength and impartiality of the legal system, and the quality of the government bureaucracy. The average of those three variables serves as a second alternative dependent variable to the CPIA cluster D score.

$X_{i t}$ represents our variable of interest for country $i$ in year $t$. As mentioned above, we test our model with the number of cumulative prior actions related to public sector governance from all DPLs approved before or during year $t$ :

$$
X_{i t}=\sum_{s=1980}^{t} n p_{i s}
$$

with $n p_{i s}$ with the number of PSG conditions for country $i$ in year $s$. This variable can be decomposed into cumulative conditions related to civil service reform, decentralization, public expenditure and financial management (PFM), anti-corruption, tax policy and administration and other public sector governance issues. This breakdown allows us to estimate the effect of PSG conditionality on four of the five CPIA cluster D components. The following dependent-independent variable pairs are tested: public expenditure and financial management conditions on CPIA's quality of budgetary management, tax policy and administration conditions on CPIA's efficiency of revenue mobilization, anti-

\footnotetext{
${ }^{8}$ Note that DPLs each specify intended results that are distinct from and broader than the prior actions contained in the loan (World Bank, 2013).
} 
corruption conditions on CPIA's accountability and corruption in the public sector, and civil service reform conditions on CPIA's quality of public administration.

$Z_{i t}$ is a vector of control variables. As other donors also might be engaged in supporting policy change, we include total aid over GDP as a control variable. Next, we also add the logarithm of GDP per capita as a regressor. High levels of per capita income could improve the quality of governance by increasing tax revenues if government funds are a binding constraint. Higher income levels could also reflect a greater volume and size of transactions, increasing the demand for more effective enforcement of contracts, public procurement of goods and services, etc. Furthermore, as many factors influence a country's welfare, GDP per capita also serves as a general control. We also include a measure of democracy, the Freedom House index of political freedoms. Finally, country and year fixed effects are added as regressors. ${ }^{9}$ Cumulative conditions is positively correlated with time, so the inclusion of year effects is important to control for any time trend or transitory events that could otherwise bias the coefficient on cumulative conditions.

We also test whether results are robust to including several additional controls. We have drawn upon the public sector reform literature to select the additional covariates. It is often argued that fiscal pressures and crises are engines for reform (see, e.g., Krueger, 1993; Ranis and Mahmood, 1992). On the other hand, crises in and by themselves do not necessarily entail deep, structural change, and could actually decrease the political capital for engaging in costly reform (Brinkerhoff, 2000; Tommasi, 2004). To control for any crisisrelated effects, we include a dummy coded 1 if a debt crisis occurred at year $t-1$. As several country cases - e.g. India, Brazil, China - suggest that economic growth may be conducive to public sector reform, we add annual GDP growth to the model. ${ }^{10}$ Schneider

\footnotetext{
${ }^{9}$ The main findings are robust to specifications without fixed effects, in which estimates are informed by cross-country variation in the data as well as over-time variation within countries. These results are available upon request.

${ }^{10}$ To avoid multicollinearity with the crisis dummy, we lag growth two periods.
} 
and Heredia (2003) argue that integration into the global economy strengthens incentives for governments to engage in PSG reform, so we include trade openness as an additional control. In addition to these economic variables, we add two political controls. Keefer (2011) and Cruz and Keefer (2013) find that governments with institutionalized parties, i.e., parties with internal accountability and sanctioning mechanisms, are more likely to pursue pro-development policies. Hence, we include a dummy for institutionalized parties in the analysis. Secondly, we add a dummy whether a country transitioned to democracy. Ideally, democratization creates electoral competition and demand for a merit-based bureaucracy. On the other hand, in young democracies, the bureaucracy could be used for electoral ends, which might hamper reform (Bunse and Fritz, 2012). Finally, we include the logarithm of population and gross IDA disbursements as additional controls. Concerning the latter, countries with higher CPIA ratings receive higher allocations of IDA aid, other things equal, which in turn may increase the likelihood of receiving a DPL with its associated conditions. Because any causal effect of CPIA ratings on DPLs (and conditions) is mediated by IDA disbursements, controlling for the latter will effectively correct for this potential source of endogeneity bias.

We estimated the model with linear, logarithmic and quadratic specifications and retained the quadratic one as it produced the best fit. The graphical output of a semiparametric estimation further justifies the choice of the quadratic model (see figure 3). From a theoretical standpoint, there may be an optimal amount of conditionality in terms of supporting policy improvements. While some conditions are undoubtedly necessary, beyond some point conditionality may become ineffective and even counterproductive in countries with limited bureaucratic capacity for implementation, and with limited political capital on the part of reform-minded leaders. An early review of adjustment lending (World Bank, 2001, pp. 79-80) notes that "[t]here is no single right number of conditions that should be included in a loan. Operational policy suggests that a priori limits on the 
number of conditions are undesirable because they tend to restrict the number of reforms that can be supported. In practice, determining what should be regarded as conditions in adjustment loans is often not straightforward...(but) many adjustment loans appear overloaded with conditions." More recently, World Bank (2015) finds a decline in recent years in the number of prior actions, intended "to strengthen the effectiveness" of DPLs "by being more selective in terms of reform focus with due consideration to the...implementation capacity" of borrowing countries. Also on the recipient side indications are found that "reform overload" may weaken the functioning of public sector institutions. In a 2014 survey of thousands of government policymakers in 130 developing countries (Parks, Bradley and Rice, Zachary and Custer, Samantha, 2015), 14.3\% of respondents reported that their government, during their time in office, had attempted "too much reform". ${ }^{11}$

Model 3.1 is tested using data from a comprehensive country-year panel of aid receiving countries from 1996 to 2008. In robustness tests, however, we employ two alternative sample restrictions. First, we drop all observations for a country after its last DPL containing PSG conditions has closed and, second, we estimate the model excluding Argentina - a strong outlier - from the sample.

\subsection{Correction for endogeneity}

When analyzing the association of World Bank lending with the quality of public sector governance, we have to take into account a potential selection bias problem. That is, countries often receive policy loans because of governance deficiencies, so the coefficient on DPL conditions may be biased downward when examining its impact on policy outcomes (Easterly, 2005). World Bank (2015) reports that the number of prior actions pertaining to macroeconomic policy reform is higher in countries with "more fragile macroeconomic policy environments." On the other hand, the coefficient on DPL conditions may be biased

\footnotetext{
${ }^{11} 40.4 \%$ of policy makers thought "too little reform" was attempted, and $45.3 \%$ reported that "about the right amount of reform" was attempted. These numbers were provided by Brad Parks and Takaaki Masaki.
} 
upward, if loans (and their associated conditions) tend to go to motivated governments that would have reformed even in the absence of support. The basic rationale of a DPL is that the prospect of receiving a loan motivates a government to implement a set of "prior actions" or policy conditions negotiated with the Bank, and funds are then disbursed in anticipation of further reforms. Conceivably, however, governments might have implemented a similar set of measures whether or not a DPL with PSG conditions had been negotiated with the Bank.

Correcting for this problem calls for a robust identification strategy. We lag the variable of interest, cumulative conditions, using both OLS and difference GMM. As the Arellano and Bond (1991) tests indicate $A R(3)$ autocorrelation, we lag number of conditions and the squared number of conditions by four periods. With difference GMM, we exploit the possibility of using deeper lags and include lags four through six. ${ }^{12}$

\section{Empirical Findings}

\section{1. $O L S$}

Table 3 presents the results of estimating the base model using OLS. We find a significant quadratic relation between PSG-related lending conditionality and the quality of public sector governance. Based on the coefficient estimates in table 3, the predicted turning point lies between 54 and 55 conditions, with the CPIA cluster D score increasing by about 0.129 points (or about 0.18 standard deviations) on average at that point, compared to the case of zero PSG conditions. Ceteris paribus, beyond 110 PSG conditions PSG lending becomes detrimental, relative to the case of no conditions. In our dataset, only five countries received more than 110 PSG conditions: Morocco (113), Pakistan (121), Ghana (136), Bangladesh (166) and Argentina (210). Table 3 also indicates that a well-governed

\footnotetext{
${ }^{12}$ To avoid an excessively large instrument matrix (Roodman, 2009), we restrict the number of lags to three.
} 
public sector is associated with high income levels, consistent with earlier findings of, e.g., Hesse (2000) and de Renzio (2009). Finally, we also find a positive partial correlation between aid and the quality of public sector governance. The positive coefficient likely reflects in part reverse causality, as better-governed countries attract larger aid allocations from donors. On the other hand, the availability of aid funds can also relax domestic resource constraints and provide a financial cushion for implementing politically-costly PSG reforms.

When testing model 3.1 with the Heritage index, equation 2 of table 3 reveals a similar quadratic relationship. The turning point lies at 63 conditions, where the Heritage score (ranging from 0 to 100) is predicted to be 4 points higher - a quarter of a standard deviation - on average than with zero conditions. The results from estimating the model with ICRG's rating over the period 1996-2008 are presented in equation 3. Again a concave relationship appears, but in this case it is not significant at conventional levels.

Results with these alternative dependent variables, produced outside the World Bank, suggest that use of the CPIA ratings does not create a strong upward bias in the measured relationship between PSG-related conditions and quality of public sector governance. Note that the GMM tests reported below provide a general correction for potential sample selection and endogeneity bias, including any bias that might be produced by CPIA ratings inflation for countries with more PSG-related conditions.

\subsection{Endogeneity of PSG conditionality and robustness tests}

Table 4 replicates the models from table 3 , but instead of using $X_{i t}$, we now lag the variable of interest four periods. Again, for two out of three governance measures - the Heritage and ICRG indexes in this case - a significant quadratic relationship appears. However, likely due to the lag length, coefficient estimates are somewhat diminished.

Table 5 presents the results of estimating model 3.1 with difference GMM, including several robustness tests described in the previous section. Because the CPIA - in compar- 
ison with the Heritage Foundation and PRS Group measures - better reflects the Bank's objectives in strengthening public sector governance, we use it as our preferred dependent variable for the difference GMM tests. A similar quadratic (and significant) relationship appears as in table 3, but with much larger effects on the quality of public sector governance. The maximum estimated impact occurs at 107 cumulative conditions, with an average increase in the CPIA cluster D score of 0.96 points (about 1.33 standard deviations) relative to no conditions. The much larger effects estimated using GMM instead of OLS is consistent with the likelihood that OLS estimates in part reflect reverse causation from lower-quality governance to more numerous PSG-related conditions.

For about $96 \%$ of the observed cases in the sample, the number of cumulative conditions is below the turning point of 107. For most but not all of the range of observed values, therefore, the estimated effect of PSG conditions on the quality of governance is positive. A possible explanation for the negative relationship estimated for the upper tail is selection bias: countries with the most severe governance problems or those most at risk of deterioration may receive loans with more stringent conditionality. If our GMM procedure fully corrected for such a bias, then few if any observations should lie above the turning point. If it is even somewhat effective in correcting for it, however, we should observe a lower turning point using OLS than GMM. In fact, that is what we observed above: the estimated turning point in OLS was 55 conditions, and $24 \%$ of observations lie beyond that point, compared to only $4 \%$ lying above the turning point estimated using GMM.

The remaining regressions in table 5 report results of several robustness tests, using GMM. First, we drop all observations for a country after the last DPL with PSG conditions to that country has closed. ${ }^{13}$ If reforms associated with DPLs are often not sustained following completion of the loan, then the estimated effects should be larger when the years following loan closing are dropped (about one-seventh of all observations). Equation

\footnotetext{
${ }^{13}$ Data on closing years were extracted from a less comprehensive dataset.
} 
2 of table 5 indeed indicates that the effect of PSG lending is larger, with the maximum impact occurring at 113 conditions, where the CPIA rating is 1.24 points on average than for the case of no conditions. This pattern of results is consistent with other statistical or anecdotal evidence of backsliding of reform after the loans are fully disbursed (see, e.g., World Bank, 1989; Rodrik, 1992; Collier et al., 1997). World Bank (2015) describes tentative findings from an ongoing study of 17 countries with multiple PEFA (Public Expenditure and Financial Accountability) assessments. In the short-term, $78 \%$ of prior actions were successful, in terms of having an impact discernible in PEFA assessments done soon after loan implementation. Impacts eroded somewhat over time, however: $71 \%$ of prior actions were successful in the medium term.

As a second sample restriction we test the model excluding Argentina from the sample. With 210 PSG conditions, Argentina can be considered an outlying observation. ${ }^{14}$ Equation 3 shows that Argentina is not particularly influential as results remain significant, and coefficients on the cumulative number of prior actions are even somewhat larger in absolute value than in the base model.

Thirdly, we test whether results are robust to including additional controls. Equation 4 of table 5 shows that coefficient estimates for the number of conditions variable remain significant, and their magnitudes are unaffected by the inclusion of the added regressors. As expected, equation 4 indicates a positive association between IDA disbursements and quality of governance. Furthermore, we find that a debt crisis negatively affects the quality of public sector governance, while growth spurts have a positive effect, possibly relaxing the political constraints by providing resources and credibility for reform. The coefficient estimate for trade openness is significantly positive, as such, we find empirical support for the hypothesis that integration into the global economy pushes governments to reform

\footnotetext{
${ }^{14}$ However, based on a visual inspection one could argue that the data on cumulative PSG lending are drawn from an exponential distribution, with the PSG loans to Argentina as part of such a data generating process. A Kolgomorov-Smirnov test does not allow us to reject this hypothesis.
} 
(although causality might run in both directions). Equation 4 also shows that none of the political variables come in significantly.

Finally, given the presence of serial correlation, we also estimate a dynamic model by including the lagged dependent variable as a regressor. ${ }^{15}$ This specification makes the stronger implicit assumption that more PSG conditions will be associated with improvements in CPIA ratings from one year to the next. Somewhat surprisingly, we find a significant short-run effect of PSG lending on governance quality (see equation 5). Computing the long-run multiplier coefficient from equation 5 results, the maximum implied effect on the CPIA rating is 1.42, somewhat larger than in the base GMM specification of equation 1 , and occurs at a slightly higher turning point of 127 cumulative conditions.

\subsection{Regime type and $P S G$ lending}

As the process of policy reform is inherently political, we test in this section whether regime type affects the strength of the relationship between PSG conditions and the qualtiy of public sector governance. We do this by estimating equation 3.1, splitting up the sample between democracies and non-democracies. To distinguish between the two regime types, we use the binary indicator developed by Cheibub et al. (2010) and estimate the difference GMM model with CPIA cluster D score as the dependent variable. We exclude from the sample countries that transitioned to and from democracy during the period 1996-2008.

Results are presented in table 6. A similar quadratic (and significant) relationship appears for democracies, with a maximum impact at 97 conditions, increasing the CPIA cluster D score with 0.64 points on average. These findings are in line with the literature that stresses the importance of inclusive political institutions for reform and growth (see, e.g., Besley and Persson, 2011). For non-democracies, no significant results are found. The linear term even comes in negatively, however, the corresponding z-score is close to 0 $(\mathrm{z}=-.11)$.

\footnotetext{
${ }^{15}$ To get a consistent estimator, we also instrument the lagged dependent variable.
} 


\subsection{Impact of PSG conditionality on cluster D components}

Prior conditions related to PSG can be disaggregated and matched with the most relevant component of CPIA Cluster D, to test for differences in their impacts. Table 7 reports results for these tests, which in all other respects replicate those from table $5{ }^{16}$ For brevity, the table reports only the coefficient estimates and standard errors for the conditions variables.

Using the base GMM specification (corresponding to equation 1 from table 5), a significant quadratic relationship between conditions and CPIA scores is found for two of the four Cluster D components, namely budgetary management and revenue mobilization. Among those two, only the results for budgetary and financial management are relatively robust to changes in the sample and the inclusion of more control variables. As seen in the first column of table 7 , however, results for the component on the quality of public administration (which focuses on human resource management and sustainability of the public sector wage bill). Vested interests, clientelism and rent-seeking behavior of public officials may partly explain the limited impact of PSG support in this sub-sector (see, e.g., Kelsall, 2011; van de Walle, 2003). IEG (2008, p. 54) notes that the Bank's analytical tools, including diagnostic instruments and monitoring indicators, are weaker in the area of administrative and civil service reform (ACSR) than in other areas such as PFM, with adverse consequences for program design.

The increased focus of the international community on public financial management - half of all PSG conditions are related to PFM reform - may help explain the positive results in this sub-sector. Compared to ACSR, there appears to be a stronger consensus among PFM specialists regarding what a well-performing system looks like, and stronger diagnostic and measurement tools. Base model estimations indicate that, on average, the

\footnotetext{
${ }^{16}$ Consistent measurement of separate CPIA criteria are available only from 1998 onwards, reducing the sample to 1291 observations.
} 
maximum predicted increase in the CPIA rating on Quality of Budgetary and Financial Management PFM component is 1.62 points, occurring at 48 PFM conditions. These findings also suggest that the positive association between CPIA cluster D scores and PSG conditionality more generally may be driven largely by prior actions that support improvements in public financial management.

Andrews (2009) distinguishes between public sector reforms involving relatively "concentrated" and "deconcentrated" sets of actors. Successful implementation of reforms is more difficult when it requires changing the behavior and norms of larger and more disparate groups of public officials or other agents. Our findings are consistent with this distinction. Among the four sub-sectors analyzed here, PFM and tax conditions appear to be the most effective in improving the quality of governance (as measured by the respective CPIA criteria), and reforms in these areas arguably involve more concentrated actors than in civil service reform and anti-corruption. Within the PFM area, ongoing work summarized in World Bank (2015) finds that prior actions focusing on "the production of laws, regulations, documents and government structures" tend to be more sustainable than those "where success depends on the performance of public officials (such as implementation of procurement systems and the credibility of the budget)."

\section{Summary and discussion}

In this study we investigate the impact of World Bank lending on the quality of public sector governance. We find a significant concave relationship between PSG conditions and quality of public sector governance. Coefficient estimates from the base GMM specification indicate that 107 PSG conditions - which is around the maximum of the predicted curve - increases the CPIA cluster D score by about 0.96 points on average, or 1.33 standard deviation units. The number of cumulative conditions is below 107 for the vast majority of observations, so the predicted effect of additional conditions is positive in most cases. This 
result is robust to sample restrictions, the use of alternative governance indicators, and the inclusion of additional controls. Replication of findings using the alternative governance measures ensures our key results do not merely reflect correlated errors in Bank staff's judgments regarding which countries should receive DPLs (with their accompanying conditions)and higher CPIA ratings. Coefficients on the conditions variables are unchanged by controlling for IDA inflows, ruling out any upward bias from the fact that countries with higher CPIA ratings receive higher IDA allocations, and potentially more DPLs.

When dropping all observations for a country after the last DPL with PSG conditions to that country has closed, the maximum impact occurs at 113 conditions, increasing the CPIA score with 1.24 points on average. This suggests that there is some backsliding of reform after the loans are fully disbursed.

We also find evidence that the impact of PSG lending is larger in democracies than in non-democracies.

When we disaggregate the analysis by the CPIA cluster D components, we find that World Bank lending appears to be most successful in improving the quality of budgetary and financial management. E.g., on average, 48 PFM conditions increase the CPIA PFM rating by 1.62 points. These results generally accord with findings from other studies on World Bank public sector reform (IEG, 2008; Blum, 2014). They also seem to indicate that the positive association between CPIA cluster D scores and PSG conditionality is driven by supporting improvements in public financial management.

To conclude, how can the World Bank become more effective in supporting public sector governance reforms, especially in the areas of corruption control and civil service reform? Its most recent public sector management strategy (World Bank, 2012) proposes several new actions and shifts in emphasis, as influenced by recent academic thinking on public sector reform, e.g. Andrews et al. (2013); Grindle (2007); Pritchett and Woolcock (2004). According to World Bank (2012), the Bank should embrace an agnostic approach towards 
PSG lending, letting go strong priors about the nature of the issue at hand and the appropriate ways to fix it. This more diagnostic, problem-solving approach would mean moving away from "best practice" towards "best fit," being more flexible in implementation, and experimenting more with novel approaches (Rodrik, 2008). As one example, Kelsall (2011) provocatively argues that instead of "going against the grain" in Africa, policy and institutional reform should rather build on local patterns of thought and governance. The author suggests that, instead of imposing an individualistic, merit-based bureaucracy, public sector reform should exploit the strong kinship ties in African societies and organize the civil service accordingly. However, Xavier (2013) cautions - while supporting most elements of the Bank's new strategy - that in some cases imported "best practice" models can provide a useful narrative that help legitimize reforms. But even in those cases, as Xavier (2013) acknowledges, reforms may fail if they are not sufficiently sensitive to local contexts and focused on solving specific problems.

The Bank's new strategy also acknowledges the need for improving risk management at the project and portfolio level, and to encourage more candid assessments of project risk by TTLs (World Bank, 2012). Next, as explicit knowledge and evidence are lacking, the Bank and other donors should invest in learning about the dynamics of public sector reform and the impact of PSG interventions. ${ }^{17}$ To achieve this, more and better data on the functioning of public sector institutions are required.

Finally, the Bank's new diagnostic, "best fit" approach envisions a more continuous dialogue with recipient country counterparts in government, and greater participation of other stakeholders including the public. A more continuous and broadened engagement of this sort by Bank task teams can generate mutual trust and help build agreement on a

\footnotetext{
${ }^{17}$ Already several initiatives are set up to improve the effectiveness of PSG lending. For instance, in 2005 the development impact evaluation initiative (DIME) was created to generate knowledge on policy effectiveness. Currently, new impact evaluations are being developed to address specific PSG bottlenecks in civil service and PFM reform.
} 
convincing diagnostic story and possible solutions that take into account incentives of key actors including politicians (World Bank, 2012).

\section{Acknowledgement}

We would like to thank Vincenzo Verardi, Adam Wagstaff, Peter Moll, Deon Filmer and two anonymous referees for useful comments and suggestions. Lodewijk is also indebted to the Institute of Development Policy and Management (University of Antwerp) and the Research Foundation Flanders (FWO) for financial support.

\section{References}

Alesina, A., Weder, B., 2002. Do corrupt governments receive less foreign aid? The American Economic Review 92 (4), pp. 1126-1137.

Andrews, M., 2009. Isomorphism and the limits to african public financial management reform. Harvard Kennedy School of Government Working Paper Series RWP09-012.

Andrews, M., 2013. Explaining positive deviance in public sector reforms in development. Harvard Kennedy School of Government Working Paper Series RWP13-040.

Andrews, M., Pritchett, L., Woolcock, M., 2013. Escaping capability traps through problem driven iterative adaptation (PDIA). World Development 51, $234-244$.

Arellano, M., Bond, S., 1991. Some tests of specification for panel data: Monte Carlo evidence and an application to employment equations. Review of Economic Studies 58 (2), 277-97.

Bambaci, J., Saront, T., Tommasi, M., 2002. The political economy of economic reforms in Argentina. Journal of Policy Refom 2 (2), 75-88.

Besley, T., Persson, T., 2011. Pillars of Prosperity. Princeton University Press, Princeton and Oxford.

Blum, J. R., 2014. What Factors Predict How Public Sector Project Perform? A Review of the World Bank's Public Sector Management Portfolio. World Bank Policy Research Working Paper 6798, World Bank, Washington DC.

Brautigam, D. A., Knack, S., 2004. Foreign aid, institutions, and governance in Sub-Saharan Africa. Economic Development and Cultural Change 52 (2), pp. 255-285.

Brinkerhoff, D. W., 2000. Assessing political will for anti-corruption efforts: An analytic framework. Public Administration and Development 20 (3), 239-252. 
Bunse, S., Fritz, V., 2012. Making public sector reforms work. Policy Research Working Paper 6174, The World Bank.

Cashel-Cordo, P., Craig, S. G., 1990. The public sector impact of international resource transfers. Journal of Development Economics 32 (1), 17 - 42 .

Cheibub, J., Gandhi, J., Vreeland, J., 2010. Democracy and dictatorship revisited. Public Choice 143 (1), $67-101$.

Clemens, M. A., Radelet, S., Bhavnani, R. R., Bazzi, S., 2012. Counting chickens when they hatch: Timing and the effects of aid on growth. The Economic Journal 122 (561), 590-617.

Collier, P., Guillaumont, P., Guillaumont, S., Gunning, J. W., 1997. Redesigning conditionality. World Development 25 (9), 1399-1407.

Cruz, C., Keefer, P., 2013. The organization of political parties and the politics of bureaucratic reform. Policy Research Working Paper Series 6686, The World Bank, Washingotn D.C.

de Renzio, P., 2009. Taking stock: What do PEFA assessments tell us about PFM systems across countries? ODI Working Papers 302.

de Renzio, P., Andrews, M., Mills, Z., 2011. Does donor support to public financial management reforms in developing countries work? ODI Working Paper 329, London.

Dreher, A., 2002. The development and implementation of IMF and World Bank conditionality. Hamburg Institute of International Economics.

Easterly, W., 2005. What did structural adjustment adjust? The association of policies and growth with repeated IMF and World Bank adjustment loans. Journal of Development Economics 76, 1-22.

Grindle, M. S., 2007. Going Local: Decentralization, Democratization, and the Promise of Good Governance. Princeton University Press.

Hesse, J. J., 2000. Rebuilding the State: Public Sector Reform in Central and Eastern Europe. Nomos, Sinzheim.

IEG, 2008. Public Sector Reform: What Works and Why? An IEG evaluation of World Bank Support. No. 6484 in World Bank Publications. The World Bank.

Kapur, D., Lewis, J. P., Webb, R., 1997. The World Bank: Its first half century. Volume 1. History. Brookings Institution Press, Washington, D.C.

Kaufmann, D., Kraay, A., Mastruzzi, M., 2006. Governance matters V: Aggregate and individual governance indicators for 1996 - 2005. World Bank Policy Research Working Paper Series 4012, Washington DC. 
Keefer, P., 2011. Collective action, political parties and pro-development public policy. Asian Development Review 28 (1), 94-118.

Kelsall, T., 2011. Going with the grain in African development? Development Policy Review 29 (s1), s223-s251.

Knack, S., 2001. Aid dependence and the quality of governance: Cross-country empirical tests. Southern Economic Journal 68 (2), 310-329.

Krueger, A. O., 1993. Political economy of policy reform in developing countries. The MIT Press, Cambridge, MA and London.

Moloney, K., 2009. Public administration and governance: A sector-level analysis of World Bank aid. International Review of Administrative Sciences 75 (4), 609-627.

OPCS, 2009. Country policy and institutional assessments: 2009 assessment questionnaire. Operations Policy and Country Services, World Bank.

Parks, Bradley and Rice, Zachary and Custer, Samantha, 2015. Marketplace of Ideas for Policy Change: Who do Developing World Leaders Listen to and Why? AidData and the College of William and Mary, Williamsburg, VA.

Pritchett, L., de Weijer, F., 2010. Fragile states: Stuck in a capability trap? Background paper for the 2011 World Development Report.

Pritchett, L., Woolcock, M., 2004. Solutions when the solution is the problem: Arraying the disarray in development. World Development 32 (2), $191-212$.

Rajan, R., Subramanian, A., 2007. Does Aid Affect Governance? The American Economic Review 97 (2), $322-327$.

Ranis, G., Mahmood, S. A., 1992. The political economy of development policy change. Basil Blackwell, Cambridge, MA and Oxford.

Remmer, K. L., 2004. Does foreign aid promote the expansion of government? American Journal of Political Science 48 (1), 77-92.

Rodrik, D., 1992. The limits of trade policy reform in developing countries. Journal of Economic Perspectives $6(1), 87-105$.

Rodrik, D., 2008. The New Development Economics: We Shall Experiment, but How Shall We Learn? Harvard Kennedy School Working Paper Series rwp08-055.

Roodman, D., 2009. A note on the theme of too many instruments. Oxford Bulletin of Economics and Statistics 71 (1), 135-158. 
Schneider, B. R., Heredia, B. (Eds.), 2003. Reinventing Leviathan: the Politics of Administrative Reform in Developing Countries. North-South Center Press, University of Miami, Miami.

Smets, L., Knack, S., 2014. World Bank lending and the Quality of Economic Policy. World Bank Policy Research Working Paper 6924, World Bank, Washington DC.

Svensson, J., 2000. Foreign aid and rent-seeking. Journal of International Economics 51 (2), 437-461.

Tommasi, M., 2004. Crisis, political institutions and policy reform: The good, the bad, and the ugly. In: Tungodden, Bertil, N. S., Kolstad, I. (Eds.), Annual World Bank Conference on Development Economics. World Bank and Oxford University Press.

van de Walle, N., 2003. Presidentialism and clientelism in Africa's emerging party systems. The Journal of Modern African Studies 41 (02), 297-321.

World Bank, 1989. Adjustment Lending: An Evaluation of Ten Years of Experience. World Bank, Washington, D.C.

World Bank, 1998. Assessing aid: What works, what doesn't, and why. Oxford University Press for the World Bank, Oxford and New York.

World Bank, 2001. Adjustment Lending Retrospective. World Bank, Washington, D.C.

World Bank, 2007. Conditionality in Development Policy Lending. World Bank, Washington, D.C.

World Bank, 2012. The World Bank's Approach to Public Sector Management 2011-2020: Better Results from Public Sector Institutions. Poverty Reduction and Economic Management, World Bank, Washington, D.C.

World Bank, 2013. Development Policy Retrospective 2012: Results, Risks, and Reforms. World Bank, Washington, D.C.

World Bank, 2015. 2015 Development Policy Financing Retrospective: Results and Sustainability. World Bank, Washington, D.C.

Xavier, J. A., 2013. The world bank approach to public sector management 20112020: lessons from the malaysian experience. International Review of Administrative Sciences 79 (3), 426-432. 


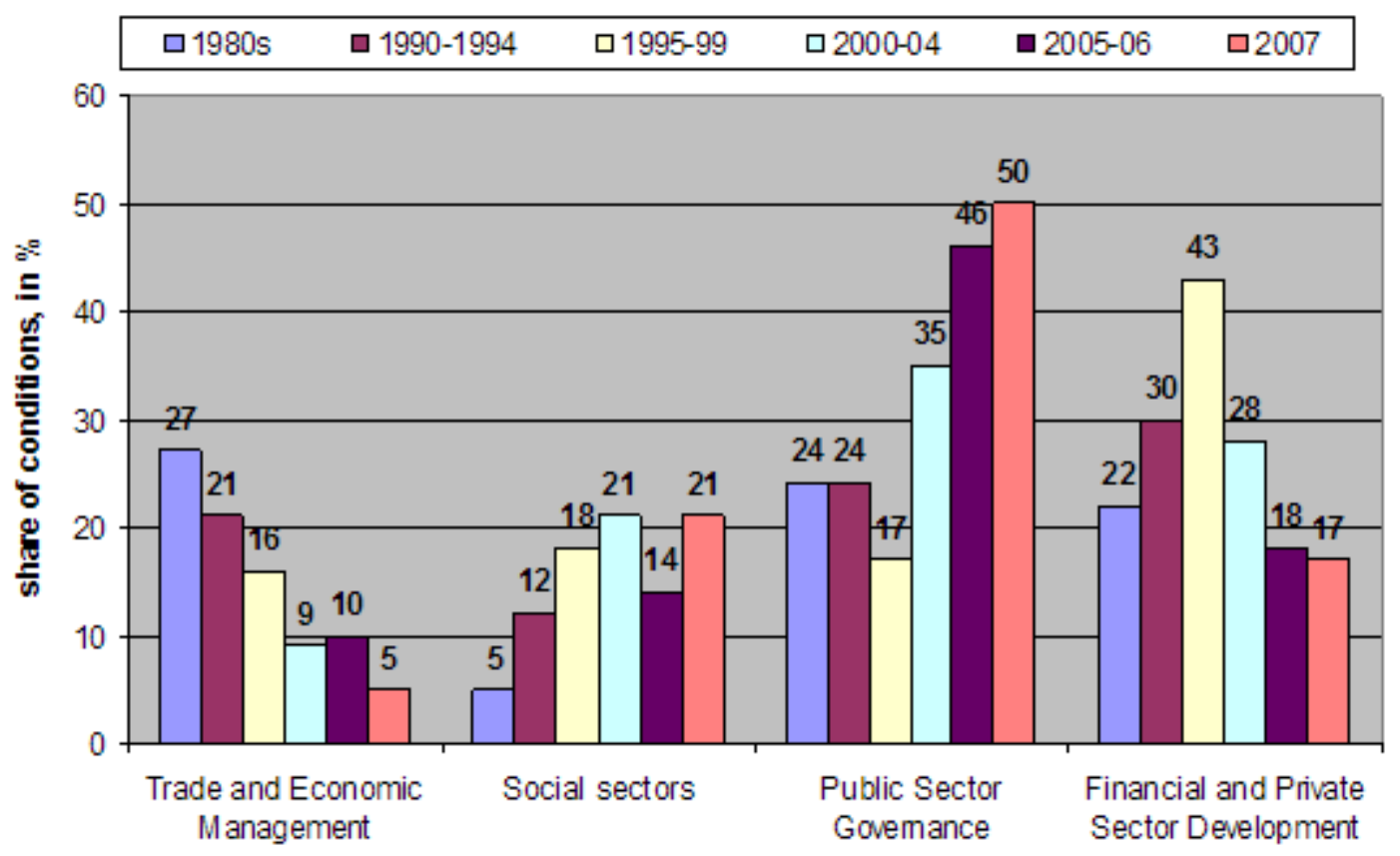

Figure 1: Sectoral coverage of conditionality in policy based lending (Source: World Bank (2007))

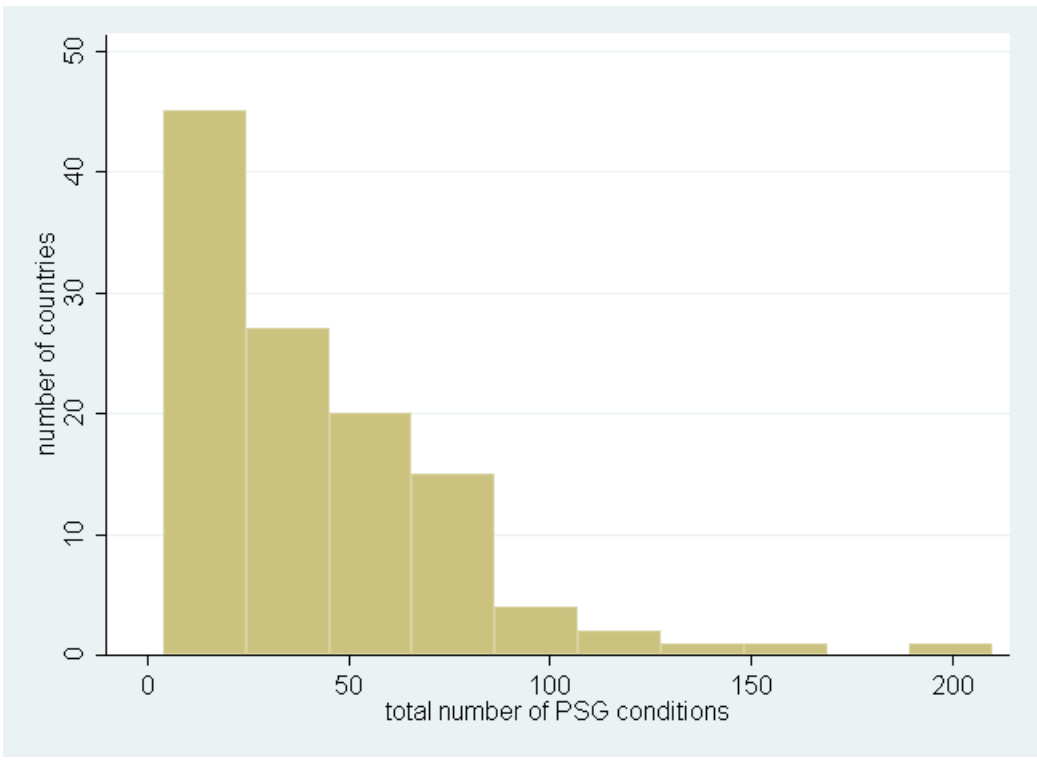

Figure 2: Distribution of cumulative PSG conditions for the period 1980-2010 
Figure 3: Non-parametric fit of cumulative conditions

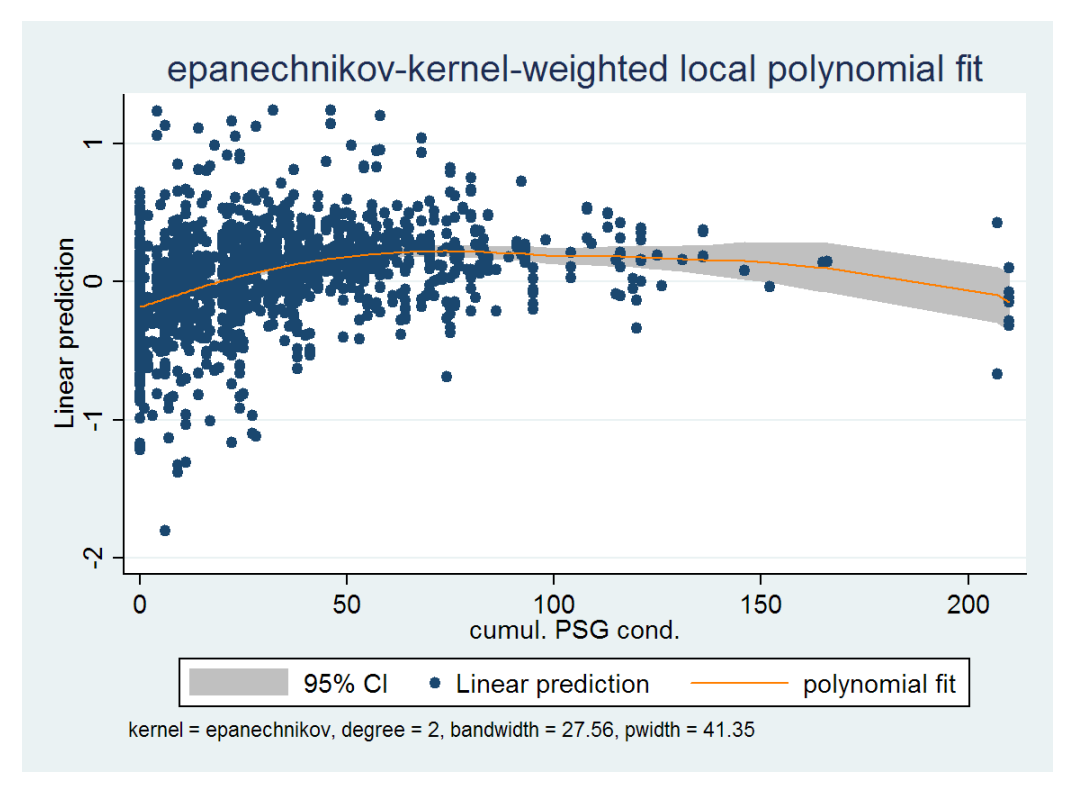

Note: semiparametric fixed-effects regression using STATA's xtsemipar command with CPIA cluster D as dependent variable, log of per capita GDP, aid/GDP, political rights and a time trend as parameterized variables and cumulative conditions as non parameterized variable. Polynomial of degree two fitted. Standard errors clustered by country. 
Table 1: sectoral distribution of all effective adjustment loans for the period 1980-2010

\begin{tabular}{rrr}
\hline \hline sector & frequency & percentage \\
\hline Agriculture and Rural Development & 62 & 6.19 \\
Economic Policy & 450 & 44.91 \\
Education & 29 & 2.89 \\
Energy and Mining & 46 & 4.59 \\
Environment & 14 & 1.4 \\
Financial Management & 1 & 0.1 \\
Financial Sector & 12 & 1.2 \\
Financial and Private Sector Development & 121 & 12.08 \\
Global Information/Communications Techn & 2 & 0.2 \\
Health, Nutrition and Population & 8 & 0.8 \\
Poverty Reduction & 51 & 5.09 \\
Private Sector Development & 7 & 0.7 \\
Public Sector Governance & 127 & 12.67 \\
Social Development & 2 & 0.2 \\
Social Protection & 49 & 4.89 \\
Transport & 5 & 0.5 \\
Urban Development & 14 & 1.4 \\
Water & 2 & 0.2 \\
\hline Total & 1,002 & 100 \\
\hline \hline
\end{tabular}


Table 2: Summary statistics

\begin{tabular}{lcccc}
\hline \hline \multicolumn{1}{c}{ Variable } & Mean & Std. Dev. & Min. & Max. \\
\hline CPIA cluster D & 3.226 & 0.717 & 1 & 5.5 \\
Heritage & 37.959 & 16.318 & 10 & 91.5 \\
ICRG & 2.581 & 0.768 & 0.667 & 5 \\
quality of public administration & 3.148 & 0.683 & 1 & 6 \\
quality of budget management & 3.345 & 0.79 & 1 & 6 \\
efficacy of revenue mobilization & 3.477 & 0.711 & 1 & 6 \\
transparancy and corruption & 3.043 & 0.796 & 1 & 6 \\
cumul. PSG cond. & 27.562 & 30.897 & 0 & 210 \\
cumul. civil service cond. & 4.576 & 6.68 & 0 & 39 \\
cumul. financial mgmt. cond. & 8.664 & 11.008 & 0 & 66 \\
cumul. tax policy cond. & 5.661 & 8.577 & 0 & 73 \\
cumul. anti-corruption cond. & 0.448 & 1.302 & 0 & 10 \\
log GDP per capita (PPP) & 8.012 & 1.017 & 5.076 & 10.352 \\
aid/GDP & 0.04 & 0.063 & -0.019 & 0.806 \\
Political Rights & 3.755 & 1.987 & 1 & 7 \\
log gross IDA & 2.102 & 2.224 & 0 & 8.311 \\
debt crisis t-1 & 0.007 & 0.085 & 0 & 1 \\
growth t-2 & 4.474 & 6.679 & -50.248 & 106.28 \\
trade openness & 0.37 & 0.212 & 0.06 & 1.162 \\
programmatic party & 0.553 & 0.497 & 0 & 1 \\
transition to democracy & 0.013 & 0.114 & 0 & 1 \\
\hline \hline
\end{tabular}


Table 3: Panel regression, OLS

\begin{tabular}{lccc}
\hline \hline Dependent variable & CPIA cluster D & Heritage & ICRG \\
\hline number of cumulative PSG conditions & .005 & .132 & .004 \\
number of cumulative PSG conditions, squared & $(.002)^{* *}$ & $(.042)^{* * *}$ & $(.003)$ \\
& -.00004 & -.001 & -.00001 \\
log GDP per capita (PPP) & $(.000009)^{* * *}$ & $(.0002)^{* * *}$ & $(.00001)$ \\
& .498 & 7.392 & .592 \\
aid/GDP & $(.139)^{* * *}$ & $(2.539)^{* * *}$ & $(.660)$ \\
& 1.525 & -9.018 & -.010 \\
Political Rights & $(.339)^{* * *}$ & $(12.151)$ & $(1.137)$ \\
& -.005 & -.302 & -.196 \\
country fixed effects & $(.021)$ & $(.404)$ & $(.056)^{* * *}$ \\
year fixed effects & $y e s$ & $y e s$ & yes \\
\hline Observations & $y e s$ & yes & yes \\
Countries & 1690 & 1607 & 1279 \\
$R^{2}$ & 139 & 132 & 108 \\
\hline \hline
\end{tabular}

* significance at $10 \%$; ** significance at $5 \%$; *** significance at $1 \%$; constant not reported. Standard errors reported in brackets are adjusted for country clustering of observations. 
Table 4: Panel regression with lagged conditions, OLS

\begin{tabular}{lccc}
\hline \hline Dependent variable & CPIA cluster D & Heritage & ICRG \\
\hline cumulative PSG conditions, t-4 & .0007 & .094 & .004 \\
squared PSG conditions, t-4 & $(.003)$ & $(.046)^{* *}$ & $(.002)^{*}$ \\
& -.00002 & -.0009 & -.00002 \\
log GDP per capita (PPP) & $(.00001)^{*}$ & $(.0002)^{* * *}$ & $(.00001)^{*}$ \\
& .515 & 7.486 & .528 \\
aid/GDP & $(.146)^{* * *}$ & $(2.592)^{* * *}$ & $(.659)$ \\
& 1.536 & -8.447 & .076 \\
Political Rights & $(.339)^{* * *}$ & $(12.277)$ & $(1.144)$ \\
& -.010 & -.451 & -.206 \\
country fixed effects & $(.021)$ & $(.401)$ & $(.058)^{* * *}$ \\
year fixed effects & $y e s$ & yes & yes \\
\hline Observations & yes & yes & yes \\
Countries & 1690 & 1607 & 1279 \\
$R^{2}$ & 139 & 132 & 108 \\
\hline \hline
\end{tabular}

* significance at $10 \%$; ** significance at 5\%; *** significance at $1 \%$; constant not reported. Standard errors reported in brackets are adjusted for country clustering of observations. 
Table 5: panel regression, difference GMM

\begin{tabular}{|c|c|c|c|c|c|}
\hline equation no. & (1) & $(2)$ & $(3)$ & (4) & $(5)$ \\
\hline variation & GMM & closing year & excl. ARG & controls & dynamic \\
\hline cumul. cond. & $\begin{array}{c}.018 \\
(.008)^{* *}\end{array}$ & $\begin{array}{c}.022 \\
(.008)^{* * *}\end{array}$ & $\begin{array}{l}.021 \\
(.010)^{* *}\end{array}$ & $\begin{array}{l}.017 \\
(.008)^{* *}\end{array}$ & $\begin{array}{c}.013 \\
(.006)^{* *}\end{array}$ \\
\hline cumul. cond, sq & $\begin{array}{l}-.00008 \\
(.00003)^{* * *}\end{array}$ & $\begin{array}{c}-.0001 \\
(.00003)^{* * *}\end{array}$ & $\begin{array}{c}-.0001 \\
(.00005)^{* *}\end{array}$ & $\begin{array}{l}-.00008 \\
(.00003)^{* * * *}\end{array}$ & $\begin{array}{l}-.00005 \\
(.00002)^{* * *}\end{array}$ \\
\hline log GDP per capita (PPP) & $\begin{array}{c}.471 \\
(.126)^{* * *}\end{array}$ & $\begin{array}{c}.476 \\
(.131)^{* * *}\end{array}$ & $\begin{array}{c}.463 \\
(.125)^{* * * *}\end{array}$ & $\begin{array}{c}.339 \\
(.108)^{* * *}\end{array}$ & $\begin{array}{c}.265 \\
(.086)^{* * *}\end{array}$ \\
\hline aid/GDP & $\begin{array}{c}1.469 \\
(.346)^{* * *}\end{array}$ & $\begin{array}{c}1.436 \\
(.358)^{* * *}\end{array}$ & $\begin{array}{l}1.455 \\
(.347)^{* * *}\end{array}$ & $\begin{array}{l}1.901 \\
(.510)^{* * *}\end{array}$ & $\begin{array}{l}.731 \\
(.313)^{* *}\end{array}$ \\
\hline Political Rights & $\begin{array}{l}.006 \\
(.023)\end{array}$ & $\begin{array}{l}.011 \\
(.023)\end{array}$ & $\begin{array}{l}.008 \\
(.024)\end{array}$ & $\begin{array}{l}.021 \\
(.021)\end{array}$ & $\begin{array}{l}.004 \\
(.012)\end{array}$ \\
\hline CPIA D, t-1 & . & . & . & . & $\begin{array}{c}.428 \\
(.104)^{* * *}\end{array}$ \\
\hline $\log$ of gross IDA & . & . & . & $\begin{array}{l}.050 \\
(.020)^{* *}\end{array}$ & . \\
\hline debt crisis t- 1 & . & . & . & $\begin{array}{l}-.280 \\
(.111)^{* *}\end{array}$ & . \\
\hline growth t-2 & . & . & . & $\begin{array}{l}.008 \\
(.002)^{* * *}\end{array}$ & . \\
\hline trade openness & . & . & . & $\begin{array}{l}.407 \\
(.211)^{*}\end{array}$ & . \\
\hline prog. party & . & . & . & $\begin{array}{l}.039 \\
(.060)\end{array}$ & . \\
\hline trans. to democ. & . & . & . & $\begin{array}{c}-.070 \\
(.087)\end{array}$ & . \\
\hline country fixed effects & yes & yes & yes & yes & yes \\
\hline year fixed effects & yes & yes & yes & yes & yes \\
\hline Observations & 1551 & 1319 & 1539 & 1399 & 1412 \\
\hline Number of countries & 139 & 135 & 138 & 127 & 139 \\
\hline Overidentifying restrictions & 32 & 32 & 32 & 32 & 48 \\
\hline Wald statistic & 132.36 & 119 & 119.66 & 185.65 & 246.89 \\
\hline p-value & .00001 & .00001 & .00001 & .00001 & .00001 \\
\hline Hansen J-test & 72.77 & 58.03 & 67.73 & 86.21 & 84.08 \\
\hline$p$-value & 0.387 & 0.846 & 0.555 & 0.091 & 0.569 \\
\hline
\end{tabular}

Note: Dependent variable: CPIA cluster D average. Cluster-robust standard errors are reported. Coefficients estimated with forward orthogonal deviations. * significance at $10 \% ;{ }^{* *}$ significance at $5 \%$; ${ }^{* *}$ significance at $1 \%$. 
Table 6: Democracy regressions

\begin{tabular}{lcc}
\hline \hline sample & non-democracies & democracies \\
\hline number of cumulative PSG conditions & -.002 & .013 \\
number of cumulative PSG conditions, squared & $(.017)$ & $(.007)^{*}$ \\
& -.00005 & -.00007 \\
log GDP per capita (PPP) & $(.0001)$ & $(.00002)^{* * *}$ \\
& .521 & .397 \\
aid/GDP & $(.217)^{* *}$ & $.206)^{*}$ \\
& 2.181 & .234 \\
country fixed effects & $(.740)^{* * *}$ & $y e s$ \\
year fixed effects & $y e s$ & $y e s$ \\
\hline Observations & $y e s$ & 644 \\
Number of countries & 615 & 59 \\
Overidentifying restrictions & 55 & 32 \\
Wald statistic & 32 & 140.59 \\
p-value & 49.49 & .00001 \\
Hansen J-test & .649 & 40.66 \\
-value & 31.66 & 0.140 \\
\hline \hline
\end{tabular}

Regression results from splitting up the sample between non-democracies $(=0)$ and democracies $(=1)$, using to Cheibub et al. (2010). Countries that transitioned to and from democracy during sample period were excluded. CPIA D used as dependent variable. Cluster-robust standard errors are reported. ${ }^{*}$ significance at $10 \%$; ${ }^{* *}$ significance at $5 \%$; $* * *$ significance at $1 \%$. 
Table 7: CPIA components

\begin{tabular}{|c|c|c|c|c|}
\hline component & public admin. & budget mgt. & revenue mobil. & transp. \& corrupt \\
\hline \multirow[t]{4}{*}{ GMM } & .050 & .068 & .102 & 1.558 \\
\hline & $(.047)$ & $(.028)^{* *}$ & $(.060)^{*}$ & $(1.030)$ \\
\hline & -.0004 & -.0007 & -.001 & -.444 \\
\hline & $(.001)$ & $(.0003)^{* *}$ & $(.0006)^{* *}$ & $(.344)$ \\
\hline \multirow[t]{4}{*}{ Closing year } & .072 & .096 & .008 & -.380 \\
\hline & $(.082)$ & $(.030)^{* * *}$ & $(.043)$ & $(.687)$ \\
\hline & -.0004 & -.001 & -.0002 & .046 \\
\hline & $(.002)$ & $(.0003)^{* * *}$ & $(.0004)$ & $(.086)$ \\
\hline \multirow[t]{4}{*}{ Excl. ARG } & .062 & .049 & .128 & 1.575 \\
\hline & $(.049)$ & $(.047)$ & $(.116)$ & $(1.034)$ \\
\hline & -.0007 & -.0004 & -.004 & -.449 \\
\hline & $(.001)$ & $(.0008)$ & $(.003)$ & $(.346)$ \\
\hline \multirow[t]{4}{*}{ Controls } & .045 & .032 & .0091 & -.208 \\
\hline & $(.048)$ & $(.019)^{*}$ & $(.049)$ & $(.133)$ \\
\hline & -.0004 & -.0004 & -.0002 & .019 \\
\hline & $(.001)$ & $(.0002)^{* *}$ & $(.0004)$ & $(.015)$ \\
\hline \multirow[t]{4}{*}{ dynamic model } & -.032 & .037 & -.003 & .822 \\
\hline & $(.052)$ & $(.020)^{*}$ & $(.039)$ & $(.457)^{*}$ \\
\hline & .0008 & -.0003 & -.00001 & -.189 \\
\hline & $(.0009)$ & $(.0002)$ & $(.0004)$ & $(.141)$ \\
\hline
\end{tabular}

Note: Results from estimating GMM models on CPIA cluster D components: Quality of Public Administration, Quality of Budgetary and Financial Management, Efficiency of Revenue Mobilization and Transparency, Accountability, and Corruption in the Public Sector. Only coefficient estimates - linear and quadratic term - and cluster-robust standard errors of conditions variable are reported. * significance at $10 \%$; ** significance at $5 \%$; *** significance at $1 \%$. 


\section{Appendices}

\section{Appendix A. Country Policy and Institutional Assessment}

The CPIA is designed to measure government policies and institutions that are believed to be important for growth and poverty reduction. The set of criteria are revised periodically to reflect changes in the collective knowledge of practitioners and specialists both inside and outside the World Bank - regarding policies and public sector management institutions that matter for these outcomes. The criteria are grouped into 4 "clusters" as follows:

- A. Economic Management

1. Macroeconomic Management

2. Fiscal Policy

3. Debt Policy

- B. Structural Policies

4. Trade

5. Financial Sector

6. Business Regulatory Environment

- C. Policies for Social Inclusion/Equity

7. Gender Equality

8. Equity of Public Resource Use

9. Building Human Resources

10. Social Protection and Labor 
11. Policies and Institutions for Environmental Sustainability

- D. Public Sector Management and Institutions

12. Property Rights and Rule-based Governance

13. Quality of Budgetary and Financial Management

14. Efficiency of Revenue Mobilization

15. Quality of Public Administration

16. Transparency, Accountability, and Corruption in the Public Sector

For each of the 16 criteria, countries are rated on a scale of 1 (low) to 6 (high) with halfpoint increments (e.g. 1.5, 2, 2.5. For the years 1995-1997, countries were rated on a scale of 1 to 5 . Scores have been rescaled for this research to a scale of 1 to 6 . See OPCS (2009) for a detailed elaboration of the scoring procedure. 